\section{Rooting Reflex}

Stephen P. Salloway

Butler Hospital Alpert Medical School of Brown University, Providence, RI, USA

\section{Definition}

The rooting reflex is elicited by stroking the cheek or corner of the mouth, causing the patients to turn and then rotate their heads, searching for the stimulating object. It is one of the frontal release signs, primitive reflexes that are normal in infants, disappear with brain maturation allowing inhibition, and reappear (are "released") in disorders that affect the frontal lobes. Like most primitive reflexes, the rooting reflex probably has evolutionary/adaptive advantages in infant apes, assisting them in searching for the nipple when nursing. It disappears at about 4 months of age in human infants.

\section{References and Readings}

Goetz, C. G. (2007). Textbook of clinical neurology (3rd ed.). Philadelphia: Saunders. 